\title{
Acercamientos críticos a la Tercera parte de la Tragicomedia de Celestina de Gómez de Toledo: nuevas perspectivas de la celestinesca
}

\author{
Juan Pablo Mauricio García Álvarez \\ Universidad de Heidelberg
}

\section{Presentación}

Con la aparición de la Segunda Comedia de Celestina se inauguró uno de los géneros literarios más prolíficos y variopintos del siglo xvi: la celestinesca, continuando sus reminiscencias en la centuria siguiente al cimentar materiales distintos que darían lugar, ya no sólo a curiosos entramados dramáticos y teatrales, sino que ayudaría a fomentar un conjunto de estrategias narrativas que funcionarán como una de las bases de la tan llamada novela moderna. Feliciano de Silva se erigirá como el primer continuador de Celestina y quien marcará la pauta literaria para los títulos descendientes directos de la obra salmantina, demostrando con ello su capacidad tanto lectora como creativa; un interprete que supo encontrar, gracias a su quehacer creativo, el puente entre ese mundo bajo representado por prostitutas, rufianes, sirvientes y mozos de espuelas con el estamento noble al que pertenecía la pareja protagonista, además de integrar en la trama de la comedia — su más importante aportación al género- la resurrección de la vieja alcahueta. Celestina se convertiría, desde este momento, en el punto de encuentro entre un texto anterior y otros nuevos que posicionaron a la vieja como la columna vertebral creativa al ser parte esencial de la acción dramática-novelesca o por las alusiones directas e indirectas después de haber sufrido una muerte trágica - aunque paródica- escrita a manos de Gómez de Toledo, responsable de la tercera entrega del ciclo celestinesco. La Tercera parte de la Tragicomedia de Celestina se convertirá en la obra donde se pone fin a la vida de Celestina, pero que, a su vez, y de forma paralela ayudará a su supervivencia y a crear una memoria literaria-cultural en los textos que componen la celestinesca. 
La continuación de Gómez de Toledo se distinguirá por cerrar los espacios vacíos y abiertos dejados por Silva, quien a la manera de los libros de caballerías dejó algunos episodios dramáticos sin solución, facilitando con ello la labor de quien podríamos llamar su seguidor —no se debe olvidar que dedica esta tercera parte al mismo Silva, además que busca su aprobación literaria-. Este hecho permitirá ofrecer nuevos cauces de la acción dramática, pero otorgando un estilo de composición original a pesar de partir de presupuestos literarios anteriores y conocidos por el público, lo que ayudaría a posicionar a sus soluciones escénicas-narrativas en un campo de expectativas que romperían con un esquema preestablecido. La principal aportación será el halo trágico otorgado a esta nueva continuación representado por la muerte de Celestina, seguido de otras como la natural inclinación al vicio y malas costumbres de los personajes pertenecientes a un estrato social bajo - regresando a lo visto en el texto salmantino - ante la inalcanzable ejemplaridad de los protagonistas y de su familia, así como la imposición del orden comunitario personificado por la institución legal —la autoridad del corregidor y del alguacil—, el enfrentamiento entre una visión de mundo caduco - encarnado en Celestinafrente a otro que se adecua a una nueva pragmática para obtener un bien material e inmaterial — personificado por los jóvenes Elicia y Albacín-, entre otros componentes que se manifiestan en esta tercera entrega del ciclo. Todo esto para dar un giro a lo expuesto por Silva en su texto en el que se privilegia una realidad más festiva y cortesana - en torno a la mesa y a la bebida, además de las historias contadas por los personajes-, junto con los requiebros amorosos de una variedad de personajes - en sus distintos niveles sociales, una especie democratización del amor-y el tratamiento humorístico que aparece en todo momento.

Por estas razones, se hace necesario e indispensable que la crítica literaria -y los mismos estudiosos de la celestinesca- comience a ofrecer nuevas lecturas analíticas y con metodologías diversas de la Tercera parte de la Tragicomedia de Celestina, no sólo por formar parte de un género imprescindible de nuestra historia literaria hispánica, sino por la manera tan particular que Gómez de Toledo configuró su obra, la trascendencia individual de ésta, y por la propuesta versátil realizada a partir de un material ampliamente conocido por el público lector y oyente de la época. Gracias al ingenio de este autor, se ofrecerá una nueva y última versión de Celestina, además de una resolución feliz para la pareja protagonista —Felides y Polandria-, debido a su unión en matrimonio público, al igual que sus sirvientes, remedo de sus señores.

Prueba de algunos aspectos aquí señalados son los trabajos que comprenden esta sección especial dedicada a la Tercera parte de la Tragicomedia de Celestina. En cada uno de estos se ofrece una interpretación analítica singular y multiforme en sus matices metodológicos, con lo que se pretende, primero, despertar el interés por parte de otros estudiosos y 
difundir un texto que ha merecido poca atención y, segundo, enriquecer la investigación de esta obra y contribuir a la bibliografía de la celestinesca en su conjunto.

En el primer trabajo de esta sección, Luis M. Esteban Martín ("Gaspar Gómez de Toledo y la búsqueda de la fama») analiza a Gómez de Toledo como un representante de la figura del autor moderno. Para ello, estudia la originalidad literaria de este escritor al cerrar de manera efectiva e ingeniosa los episodios que habían quedado abiertos en la Segunda Comedia de Celestina de Feliciano de Silva, además presta atención a la forma en que se configuran los personajes desde una perspectiva más realista y menos artificial en comparación con la entrega anterior del ciclo; así, Gómez de Toledo regresa a los entes de ficción su naturaleza inicial, más acorde al texto paradigma, con lo que se hace patente una sistematicidad del comportamiento según su estrato social y económico del mundo caótico que se intenta transmitir. Por otra parte - y derivado de lo anterior-, Esteban Martín relaciona la importancia de la imprenta como difusora de los textos literarios con la intención por satisfacer las expectativas de un público consumista —en un sentido material del libro y otro estilístico-literario- presente en la mentalidad de Gómez de Toledo, revelando con esto una "consciencia de autor» que hace palpable la idea de un pensamiento moderno de la literatura, entendiendo por esto, según el crítico, a la preocupación tácita en el texto de Gómez de Toledo por posicionarse como una autoridad creativa al redirigir de manera original a lo ya preestablecido en la obra de Silva.

Rosa Navarro Durán - a quién debemos la más reciente edición de la Tercera parte de la Tragicomedia- estudia la propuesta crítica que Gómez de Toledo hace de su modelo inmediato anterior y de la tradición del teatro humanístico — por ejemplo, Comedia Thebaida, la Aquilana y la Vidriana- para componer su obra y devolver el decoro al estrato noble con la finalidad de restaurar el orden social diluido por la inventiva de Feliciano de Silva. Bajo esta premisa, en este artículo ("Siguiendo el guión, pero guardando el decoro: cuchilladas y libreas en la Tercera Celestina») se analizan los mecanismos literarios utilizados por Gómez de Toledo para ofrecer la imagen tópica del enamorado celestinesco, la actitud ambiciosa y problemática característica de los personajes socialmente bajos y las variedades lingüísticas con las cuales se expresan, lo que ayudará a marcar el distanciamiento de estos con quienes son parte del estamento noble. Además, se resalta la actuación activa de Polandria al convertirse en el actante que persuade a Felides para indicarle que Celestina deberá desempeñar el papel de casamentera para concretar su matrimonio público. Otro elemento de análisis será la tipificación de los rufianes, rameras y la misma Celestina como personajes de entremés o de comedia debido a los castigos y a las situaciones que adquieren una naturaleza cómica. Navarro Durán demuestra que el decoro funcionará 
como un condicionamiento de la realidad textual sobre el cual se configura esta continuación celestinesca.

La nueva configuración del mundo marginal y su representación en la Tercera parte de la Tragicomedia serán el foco de atención del trabajo de Folke Gernert ("Crimen y castigo en la Tercera Celestina de Gaspar Gómez de Toledo: ¿la visión moralizadora de un médico?»), quien analiza la figura de Celestina y el discurso alrededor de ésta. Este personaje se caracterizará por la concentración de valores morales negativos que se reflejan tanto en su decrepitud física como en los vicios — sobre todo la bebida—; será tal el grado de descomposición social de Celestina que Gómez de Toledo creará algunos episodios en que la vieja será víctima de castigos corporales, algunos rayando en lo escatológico, con lo cual necesitará remedios para curar sus heridas y que son pronunciados por otros personajes o por la misma vieja. Estos pasajes, como demuestra Gernert, serán altamente significativos porque podrían revelar la respuesta a una posible hipótesis sobre el conocimiento médico del autor, pues es claro el uso discursivo de un campo semántico propio de la medicina de la época.

En el último artículo de esta sección, Juan Pablo Mauricio García Álvarez ("Materialización del dolor de Celestina en la Tercera parte de la Tragicomedia de Celestina») estudia el dolor que sufre Celestina a lo largo de la obra de Gómez de Toledo como elemento estructural del personaje. Las heridas físicas y emocionales de las cuales es víctima la vieja por parte de Pandulfo y otros rufianes — venganzas personales-, además de la sentencia judicial por pena de lenocinio — vejación pública—, permiten, según el autor, hablar de una cultura emocional en esta continuación celestinesca. El dolor se materializará en objetos determinados — cuerpo de Celestina, vestimenta, entre otros-y se manifiestará en espacios particulares, haciendo una distinción entre lo privado y lo público. Por tanto, la emoción y las sensaciones ayudarán a percibir el sentido trágico con el cual se caracteriza a Celestina en esta tercera entrega del ciclo celestinesco.

Los trabajos aquí reunidos permiten dar cuenta de la originalidad del texto celestinesco de Gómez de Toledo. Más allá de su aportación más emblemática al género: la muerte de Celestina, en el texto se hace eco de una diversidad de temáticas y materiales que nos permiten posicionar a la Tercera parte de la Tragicomedia de Celestinesca como una obra experimental en varios sentidos. Por ejemplo, las estrategias literarias utilizadas por Gómez de Toledo para adecuar su obra a un ciclo y posicionarse como el creador de un estilo literario propio, o la búsqueda por resolver preocupaciones textuales y volver al texto su naturaleza trágica, pero con escenas cómicas que darán cuenta de algunas convenciones propias de géneros teatrales que aún están por construirse. $\bigcirc$ también la importancia del cuerpo Celestina al constituirse como receptáculo de una serie de valores morales que harán mella en su personalidad hasta derivar en su muerte, aspectos que permiten cuestionar el nivel semán- 
tico del discurso utilizado para la obra y los alcances significativos que exterioriza la vieja antes de su final trágico. Este conjunto de lecturas críticas trata de invitar tanto a la investigación de esta Tercera parte como a su lectura, la cual aún guarda sorpresas en un sentido unitario y en otro integral de la celestinesca.

Por último, quiero agradecer a José Luis Canet, su generosidad y apoyo en todo momento para la realización de este proyecto. De igual forma quiero extender mi agradecimiento a cada uno de los participantes del mismo. 
